\title{
FATORES ASSOCIADOS AOS ACIDENTES BIOLÓGICOS ENTRE PROFISSIONAIS DE ENFERMAGEM
}

\begin{abstract}
Suzana de Almeida Fráguas Simão ${ }^{1}$ Vanessa de Souza², Rhiva Alves Amaral Borges², Cátia Regina Garcia Soares²,
\end{abstract} Elaine Antunes Cortez ${ }^{3}$

\begin{abstract}
RESUMO: A intensa rotina de atividades exercidas pelos profissionais de enfermagem nas emergências hospitalares pode aumentar o risco de um acidente pela sobrecarga de trabalho. Esta pesquisa teve como objetivo investigar fatores relacionados à ocorrência de acidentes com material biológico entre 101 profissionais de enfermagem atuantes em unidade de emergência. Os resultados evidenciaram que os sujeitos relacionaram a necessidade de agilidade na execução das atividades; a carga horária elevada e o reencape de agulhas como as principais causas de acidentes. Ressaltamos a grande importância de implementação de programas de orientação e treinamento, a fim de minimizar esses agravos à saúde dos trabalhadores.
\end{abstract}

PALAVRAS-CHAVE: Riscos ocupacionais; Exposição a agentes biológicos; Enfermagem.

\section{FACTORS RELATED TO BIOLOGICALACCIDENTS AMONG PROFESSIONAL OF NURSING}

\begin{abstract}
The intense routine of tasks performed by the nursing professionals in emergency hospital units increases the risk of an accident because of the work overload. This research aims to identify and analyze the occurrence, among the nursing team, of work accidents with biological material at the emergency hospital units. The study had a sample of 101 employees of the nursing team. The results showed that accidents related to the need for agility in the execution of activities, the shifts of 24 hours, and recapping of needles, are the major causes of accidents. It is important to emphasize the importance of implementation of guidance and training to minimize those rates.
\end{abstract}

KEYWORDS: Occupational risks; Exposure to biological agents; Nursing.

\section{FACTORES ASSOCIADOS A LOS ACCIDENTES BIOLÓGICOS ENTRE PROFESIONALES DE ENFERMERÍA}

RESUMEN: La intensa rutina de actividades ejercidas por los profesionales de enfermería en las emergencias hospitalarias puede aumentar el riesgo de un accidente por la sobrecarga de trabajo. Esta investigación tiene como objetivo investigar factores relacionados a la ocurrencia de accidentes con material biológico entre 101 profesionales de enfermería actuantes en unidad de emergencia. Los resultados mostraron que los sujetos relacionaron la necesidad de agilidad en la ejecución de las actividades, la carga horaria elevada y el reencape de agujas como las principales causas de los accidentes. Resaltamos la gran importancia de la implementación de programas de orientación y capacitación para reducir esos agravios a la salud de los trabajadores.

PALABRAS CLAVE: Riesgos laborales; Exposición a Agentes Biológicos; Enfermería.

${ }^{1}$ Enfermeira. Mestranda em Enfermagem da Universidade Federal Fluminense-UFF.

${ }^{2}$ Enfermeira. Discente do Curso de Especialização em Controle de Infecção em Assistência à Saúde-UFF.

${ }^{3}$ Enfermeira. Doutoranda em Enfermagem na Universidade Federal do Rio de Janeiro-UFRJ.

Autor correspondente:

Elaine Antunes Cortez

Universidade Federal do Rio de Janeiro

Rua Dr. Catrambi, 240/102 - 20531-005 - Rio de Janeiro-RJ, Brasil

Recebido: 10/07/09

E-mail: nanicortez@hotmail.com

Aprovado: 21/01/09 


\section{INTRODUÇÃO}

Em função dos ambientes hospitalares serem complexos e considerados insalubres, os trabalhadores atuantes estão expostos a inúmeros riscos durante o desenvolvimento de seu processo de trabalho. Como resultados, existem riscos potenciais aos quais podem estar expostos, dependendo da atividade que desenvolvem $^{(1)}$.

Apesar dos profissionais de saúde estarem em constante risco de adquirir infecções, somente com o advento dos primeiros casos relatados de doentes acometidos pela Síndrome da Imunodeficiência Adquirida-Aids, em 1981, surgiu grande preocupação e medo do contágio por acidente quando estes prestam cuidados a pacientes com tal diagnóstico ${ }^{(2)}$. No Brasil, o primeiro caso de contaminação foi notificado em 1997, referindo-se a uma auxiliar de enfermagem contaminada pelo vírus HIV, com confirmação de Aids, devido a um acidente de trabalho com material perfurocortante ocorrido em 1994, em São Paulo(3).

Outro destaque é que a hepatite $\mathrm{B}$ de origem profissional é mais freqüente entre os trabalhadores de saúde. Em relação à população geral, o risco de hepatite B é 11 vezes mais elevado entre o pessoal de saúde, em especial os trabalhadores de laboratório e de enfermagem ${ }^{(4)}$.

As doenças ocupacionais e os acidentes de trabalho constituem um importante problema de saúde pública em todo o mundo. As estimativas da Organização Internacional do Trabalho revelam a ocorrência anual de 160 milhões de doenças ocupacionais, 250 milhões de acidentes de trabalho e 330 mil óbitos, baseando-se somente em doenças não transmissíveis ${ }^{(5)}$.

Embora acidentes com material biológico não se enquadrem na definição legal de acidente de trabalho, o registro junto à Medicina do Trabalho e Comissão de Controle de Infecção Hospitalar é fundamental, considerando-se suas consequências.

No Brasil, a promulgação da Constituição brasileira, em 1988, representou importante marco na atenção à saúde do trabalhador, uma vez que o trabalho é um determinante/condicionante da saúde dos indivíduos e que a saúde dos trabalhadores deve ser viabilizada pelo Sistema Único de Saúde, segundo os princípios que o orientam ${ }^{(6)}$.

Os acidentes ocasionados com agulhas são responsáveis por 80 a $90 \%$ das transmissões de doenças infecciosas entre trabalhadores de saúde. O risco de transmissão de infecções por meio de agulhas contaminadas é de um em três para Hepatite $B$, um em trinta para Hepatite $\mathrm{C}$ e um em trezentos para $\mathrm{HIV}^{(7)}$.

Ademais, outro agravante do risco entre trabalhadores da área da saúde é o contato direto com microrganismos, transmitidos a partir de fontes de infecção não identificadas, como pacientes com diagnósticos não definidos, ou ainda problemas estruturais que habitualmente são encontrados em unidades hospitalares. O contato com microrganismos patogênicos ocorre, com frequência, na execução do trabalho de enfermagem.

Conforme as estatísticas observadas, a equipe de enfermagem é uma das principais categorias profissionais sujeitas às exposições com material biológico. Este fato relaciona-se à Enfermagem ser a profissão da área da saúde a ter mais contato direto na assistência aos pacientes e também ao tipo e à frequência de procedimentos realizados ${ }^{(2)}$.

Diante do exposto, é importante salientar que o emprego de práticas seguras e o uso de equipamentos de proteção adequados reduzem significativamente o risco de acidente ocupacional, fazendo-se necessária também a conscientização dos profissionais para utilização de técnicas assépticas e o estabelecimento de normas de conduta e procedimentos que garantam ao profissional e ao paciente um tratamento sem risco de contaminação ${ }^{(8)}$.

Por isso, para se evitar o risco de exposição a material biológico, todo profissional deve ter à sua disposição Equipamentos de Proteção Individual (EPI), instrumentos de uso pessoal, cuja finalidade é neutralizar a ação de certos acidentes possíveis de causar lesões ao trabalhador e protegê-lo contra prováveis danos à saúde, causados pelas condições de trabalho ${ }^{(9)}$.

São recomendados alguns cuidados para o manuseio de materiais perfurocortantes e com a máxima atenção durante a realização dos procedimentos; nãoutilização de dedos como anteparo durante a realização de procedimentos; não reencapar, entortar, quebrar ou retirar agulhas da seringa com as mãos; todo material mesmo que estéril deve ser desprezado em recipientes específicos para o seu descarte, sendo os recipientes colocados sempre próximos do local onde é realizado o procedimento $^{(10)}$.

Ainda, como medida preventiva, todo trabalhador de serviços de saúde deve receber, gratuitamente, imunização ativa contra tétano, difteria, hepatite B e os estabelecidos no Programa de Controle Médico de Saúde Ocupacional. Sempre que houver vacinas eficazes contra outros agentes biológicos a que os 
trabalhadores estão ou poderão estar expostos, o empregador deve fornecê-las gratuitamente ${ }^{(11)}$.

Esta pesquisa teve como objetivo investigar fatores relacionados à ocorrência de acidentes com material biológico entre profissionais de enfermagem atuantes em unidade de emergência.

\section{MATERIAL E MÉTODOS}

Trata-se de um estudo descritivo exploratório, com abordagem quantitativa. Foi realizado em um hospital geral público da região metropolitana do Estado do Rio de Janeiro, de agosto a setembro de 2008, após aprovação pelo Comitê de Ética em Pesquisa sob protocolo n ${ }^{2}$ 57-A/08 em 22/07/2008.

A população estudada foi composta pelos profissionais de enfermagem que atuam diretamente no serviço de emergência da unidade. Fizeram parte do estudo 101 sujeitos, sendo 60 auxiliares de enfermagem, 16 técnicos em enfermagem e 25 enfermeiros, que atenderam aos seguintes critérios de inclusão: atuar no serviço investigado e na área de emergência há, no mínimo, seis meses consecutivos; estar de plantão no momento da entrevista; concordar em participar do estudo, após esclarecimento verbal e escrito sobre a pesquisa.

Utilizou-se um roteiro estruturado, o qual foi elaborado com base na literatura pertinente e vivência das autoras. Esse instrumento foi encaminhado para validação de conteúdo, por três peritos na temática e em metodologia da pesquisa, para verificar seu potencial alcance dos objetivos traçados para este estudo. Os dados foram armazenados em banco de dados, utilizando a planilha eletrônica MicrosoftExcel 2000 e, posteriormente, analisados no programa Epi info versão 3.4.3; assim, foram dispostos em tabelas e analisados por meio de estatística descritiva.

\section{RESULTADOS}

Os dados foram agrupados de acordo com a especificidade das respostas, abrangendo: causas do acidente, carga horária e motivos citados como relevantes para tais ocorrências.

Em relação aos fatores contribuintes à ocorrência dos acidentes, foi possível identificar que $57,7 \%$ dos entrevistados relacionaram à necessidade de agilidade na execução das atividades; $23,1 \%$ ao cansaço físico e mental; 11,5\% à ausência de EPI; e 7,7\% à pouca experiência profissional (Gráfico 1).

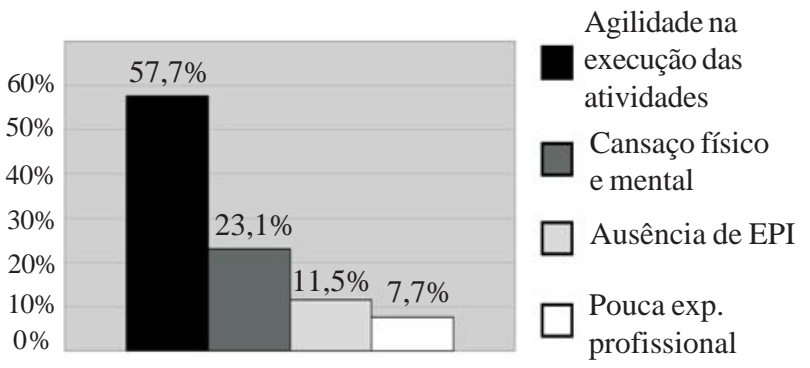

Gráfico 1 - Principais fatores contribuintes para ocorrência de acidentes com material biológico. Rio de Janeiro, 2008.

Quanto à carga horária de trabalho, é importante ressaltar que 52,3\% dos profissionais realizam plantão de 24 horas, 45,4\% plantão de 12 horas e apenas 2,3\% plantão de seis horas, como demonstra o gráfico 2.

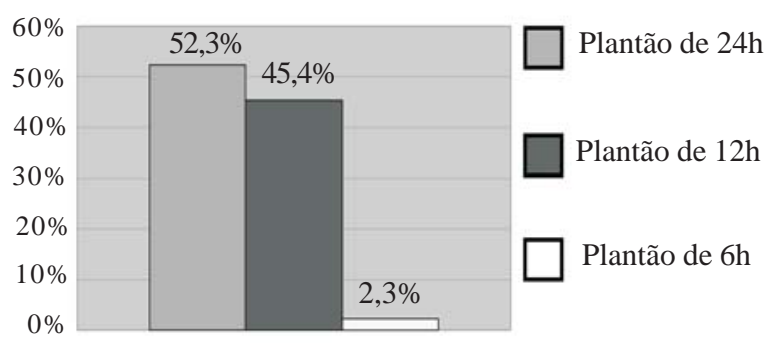

Gráfico 2 - Distribuição dos acidentes com material biológico, segundo a carga horária de trabalho dos profissionais de enfermagem. Rio de Janeiro, 2008.

No que concerne às causas dos acidentes percebidas, o gráfico 3 mostra ser o re-encape (38,6\%), seguido por movimentação do paciente no leito $(29,5 \%)$, ocasionados por terceiros $(22,7 \%)$, por descarte inadequado $(4,5 \%)$ e ausência ou uso inadequado de EPI (4,6\%).

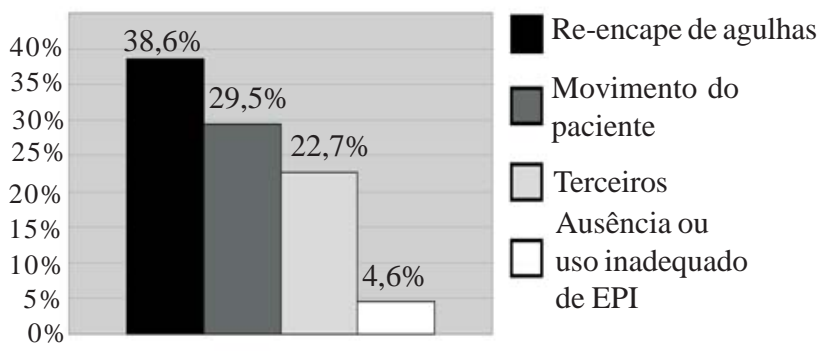

Gráfico 3 - Distribuição dos acidentes com material biológico, segundo a causa. Rio de Janeiro, 2008.

\section{DISCUSSÃO}

Os resultados encontrados caracterizam a distribuição dos principais fatores para a ocorrência de acidentes envolvendo material biológico entre a equipe de enfermagem. Assim, foi possível traçar os 
principais problemas nas atividades rotineiras, percebidas pelo grupo investigado como fatores que favorecem a ocorrência deste tipo de acidente laboral.

No que se refere aos profissionais de saúde como um todo, a precariedade das condições de trabalho, somadas à dificuldade de convivência com os colegas de profissão, acarretam prejuízos na vida cotidiana privada. Tendo em vista a permanência no hospital, devido às escalas extras de plantões, esses trabalhadores se vêem forçados a abdicar do seu lazer em prol de melhores condições salariais. Para isso, sacrificam parte do tempo dedicado à convivência familiar, o que gera um sentimento de vazio e fragilização dos laços afetivos ${ }^{(12)}$.

A duplicidade de emprego, necessária à sobrevivência nos dias atuais, em virtude da redução do poder aquisitivo da população (notadamente aos baixos salários proporcionados pela conjuntura econômica e social que o Brasil apresenta no momento), desgasta a condição física e psíquica dos profissionais ${ }^{(13)}$. Portanto, a necessidade de mais um emprego exige do profissional de enfermagem a permanência da maioria dos seus anos produtivos em ambiente insalubre, o que aumenta o tempo de exposição aos riscos ocupacionais.

Os acidentes envolvendo agulhas são os principais responsáveis por expor os profissionais de saúde ao risco de adquirir infecções graves como a Aids e hepatite $\mathrm{B}$ e $\mathrm{C}^{(14)}$. Ainda assim, procedimentos de risco como o reencape de agulhas é prática rotineira. Cabe destacar que o descarte inadequado de objetos perfurocortantes também é um fator envolvido, embora pesquisadores relacionem a introdução ao uso de recipientes padronizados para descarte desse tipo de objeto como fator de incentivo ao descarte apropriado, evitando parte dos acidentes por esse motivo ${ }^{(15)}$.

Desta forma, medidas preventivas são importantes, necessárias e eficazes para redução de acidentes com perfurocortantes, cabendo ao enfermeiro o planejamento e implementação destas.

\section{CONCLUSÃO}

A partir dos dados encontrados, foram descritas e discutidas as ocorrências desse tipo de acidente com os profissionais de enfermagem, fatores relacionados aos mesmos, carga de horária de trabalho dos envolvidos e, ainda, a forma como ocorreram os acidentes.

Os fatores relatados que, segundo os profissionais da pesquisa, contribuem para a ocorrência dos acidentes entre a equipe de enfermagem foram, em ordem crescente: pouca experiência profissional, ausência de EPI, cansaço físico e mental e necessidade de maior agilidade de realização das atividades de rotina em um setor de emergência. No que concerne às causas dos acidentes, o reencape de agulhas, seguido da movimentação dos pacientes, foram os mais evidenciados.

É preciso valorizar a participação dos enfermeiros como educadores, sendo de extrema importância o paradigma nas práticas de saúde do trabalhador. A educação em saúde, caracterizada por propostas de mudanças, desde as atividades nas instituições de ensino, como a adoção de medidas preventivas de biossegurança no ato de cuidar do cliente, é essencial e pertinente na formação do enfermeiro e demais elementos da equipe de enfermagem.

Os estudos de acidentes de trabalho na equipe de enfermagem requerem a consideração de diversas variáveis, pois esta categoria profissional é constituída por trabalhadores com formação educacional e inserções socioculturais distintas.

\section{REFERÊNCIAS}

1. Nishide VM, Benatti MCC, Costa NM. Ocorrência de acidente do trabalho em uma unidade de terapia intensiva. Rev Latino-Am Enfermagem. 2004;12(2):82-9.

2. Ministério da Saúde (BR). Programa Nacional de Hepatites Virais. Avaliação da Assistência às Hepatites Virais no Brasil. Brasília; 2002;1-61.

3. Associação Brasileira de Enfermagem. Seção RJ. Cartilha do trabalhador de enfermagem: saúde, segurança e boas condições de trabalho. Rio de Janeiro;2006.

4. DoAN, CiesielskiCA, Metler RP, HammettTA, LI J, Fleming PL. Occupational acquired human immunodeficiency virus (HIV) infection: national case surveillance data during 20 years of the HIV epidemic in the United States. Infec Control Hosp Epidemiol. 2003; 24(2):86-96.

5. Gasparini LR. Controle de infecção. São Paulo: BD; 2005.

6. Costa, TF, Felli VEA. Exposição dos trabalhadores de enfermagem às cargas químicas em um hospital público universitário da cidade de São Paulo. Rev Latino-Am Enfermagem. 2005;13(4):501-8.

7. Godfr K. Sharp practice. Nurs Times. 2001;97(2):22-4.

8. SENAI - CE. Prevenção de acidentes para componentes da CIPA - Segurança. Fortaleza (CE): Ética; 2000. 
9. Ministério da Saúde (BR). Manual de DST. 2009; [acesso em 2009 Ago 10]. Disponível: http://www.aids.gov.br/ assistencia/manualdst/item11.htm.

10. Ministério da Saúde (BR). Programa Nacional DST/ Aids. Secretaria de Vigilância em Saúde. Programa Nacional para a Prevenção e o Controle das Hepatites Virais. Departamento de Vigilância Epidemiológica. Secretaria de Vigilância em Saúde. Recomendações para atendimento e acompanhamento de exposição ocupacional a material biológico: HIV e Hepatite B e C. Brasília; 2004.

12. Oliveira BRG, Murofuse NT. Acidentes de trabalho e doença ocupacional: estudo sobre o conhecimento do trabalhador hospitalar dos riscos à saúde de seu trabalho. Rev Latino-Am Enfermagem. 2001; 9(1):109-15.

13. Lima FA, Pinheiro PNC, Vieira NFC. Acidentes com materiais perfurocortantes: conhecendo os sentimentos e emoções dos profissionais de enfermagem. Escola Anna Nery Rev Enferm. 2007;11(2):205-11.

14. Brevidelli MM, Cianciarullo TI. Análise dos acidentes com agulhas em um hospital universitário: situações de ocorrência e tendências. Rev Latino-Am Enfermagem. 2002;10(6):780-6.

15. Oliveira BAC, Kluthcovsky ACGC, Kluthcovsky FA. Estudo sobre a ocorrência de acidentes de trabalho com material biológico em profissionais de enfermagem de um hospital. Cogitare Enferm. 2008 Jan/Mar;13(2):194-205. 